\title{
A EDUCAÇÃO NA REVISTA A DEFESA NACIONAL: 1913-1945
}

\author{
José Antonio Sepulveda ${ }^{1}$
}

\begin{abstract}
RESUMO
O objetivo deste trabalho é identificar dentro do campo militar a importância dada à educação como elemento de formação do campo, e como instrumento para o desenvolvimento do Brasil. Este texto pretende expor e analisar as diferentes concepções de educação defendidas pelos militares, mais especificamente aquelas difundidas pela revista A Defesa Nacional a partir de 1913, ano de sua inauguração, até o fim da Segunda Guerra, 1945, compreendendo o período que efetivamente as Forças Armadas ganharam força na sociedade brasileira. Portanto, este é um trabalho de análise documental que tem a história como seu principal objeto. As principais referências teóricas são baseadas em Pierre Bourdieu e Jacques Le Goff. Como conclusão verificou-se que o tema "educação" esteve constantemente em foco na revista A Defesa Nacional. Vale ressaltar, que apesar da educação aparecer, por vezes, secundarizada nos artigos, não diminuía a sua importância, principalmente, pela ênfase dada a função regularizadora e moral que ela pode proporcionar à sociedade.

Palavras-chave: Educação; Militares; Revista A Defesa nacional.
\end{abstract}

\section{EDUCATION IN DEFENDING NATIONAL JOURNAL: 1913-1945}

\begin{abstract}
The objective of this work is to identify within the military field the importance given to education as part of the field's construction, and as an instrument for the development of Brazil. This text seeks to expose and analyze the different conceptions of education advocated by the military, more specifically those broadcast by National Defense magazine from 1913, the year of its inception until the end of the War, in 1945, comprising the period that effectively forces armed gained strength in Brazilian society. So this is a work of documentary analysis that has history as its main object. The main theoretical references are based on Pierre Bourdieu and Jacques Le Goff. In conclusion it was found that the theme "education" was constantly in focus in the journal The National Defence. It is noteworthy that although education appears sometimes sidelined in the articles, did not diminish its importance, mainly for emphasis of the moral function and what it can offer to society.
\end{abstract}

Keywords: Education; Military; National Defense Magazine

Este texto pretende expor e analisar as diferentes concepções de educação defendidas pelos militares, mais especificamente aquelas difundidas pela revista A Defesa Nacional a partir de 1913, ano de sua inauguração, até o fim da Segunda Guerra, 1945, compreendendo o período que efetivamente as Forças Armadas ganharam força na sociedade brasileira. A proposta deste trabalho, então, é identificar dentro do campo militar $^{2}$ a importância dada à educação como elemento de formação do campo, e como instrumento para o desenvolvimento do Brasil. Tal revista foi criada por um grupo especial de militares que contribuíram para a modernização do Exército, e esse grupo tem uma história muito peculiar. 
Em 1908, o então Ministro da Guerra Hermes da Fonseca viajou para a Europa na busca de material bélico moderno e de novos conhecimentos técnico-profissionais. Admirador de Bismarck e do Exército Prussiano, ele estabeleceu contato com a Alemanha e selou um acordo que propunha o aperfeiçoamento de quadros do Exército brasileiro através de estagiários em missão de estudo.

Pela experiência de estágio na Alemanha, os oficiais que voltavam reforçavam o discurso modernizador das Forças Armadas. O contato com a prática militar, estratégia, tática e operacionalidade bélica tornou esses tais oficiais conhecedores das mais modernas técnicas militares. Outra experiência significativa foi o contato com a literatura europeia sobre a formação militar para a guerra e sobre a função profissional do militar, com destaque para o histórico posicionamento do exército alemão na formação da nação. Esses militares garantiriam grande impulso ao processo de modernização do Exército através da reprodução no Brasil de seu aprendizado (BARONI, 2008).

Os estagiários, embora em pequeno número e em alguns casos com grandes dificuldades acerca do entendimento do idioma, são ainda hoje exaltados pelo Exército como fonte inaugural do seu processo de modernização, apesar de terem sido relativamente hostilizados quando os primeiros grupos voltaram para o Brasil, sendo chamados de "jovens turcos" . A bandeira de luta desses jovens oficiais era a difusão de seu aprendizado através do contato direto com a tropa, da atuação na Escola Militar, principalmente, entre 1919-22, e a fundação da revista A Defesa Nacional, esta última servindo de instrumento para veiculação do pensamento renovador militar (LEMOS, 1999).

A revista, fundada em 1913, foi organizada pelo último grupo enviado para o estágio na Alemanha e se apresentava como plataforma de lançamento para suas ideias militares nacionalistas e como instrumento de intervenção na política nacional. Dentre os seus membros estavam: Bertholdo Klinger, Euclydes de Oliveira Figueiredo e Estevão Leitão de Carvalho, além de alguns militares que, embora não tenham feito parte do estágio, compartilhavam de seus ideais. Sua organização legal é a Cooperativa Militar Editora e de Cultura Intelectual "A Defesa Nacional”, pessoa jurídica e de direito privado.

No momento de sua fundação, os redatores eram fixos. $\mathrm{O}$ grupo mantenedor era constituído por Bertholdo Klinger, Estevão Leitão de Carvalho, Joaquim de Souza Reis, Francisco de Paula Cidade, Mário Clementino, Lima e Silva, Parga Rodrigues, Jorge Pinheiro, Pompeu Cavalcanti, Euclydes Figueiredo, Brazilio Taborda, Amaro Vila Nova e Maciel da Costa. A periodicidade da revista foi alterada algumas vezes, sendo mensal de 1913 a 1945.

Os temas partiam de premissas claramente anunciadoras da nova concepção de defesa nacional e da efetiva participação militar na vida interna do país, inclusive com uma função educadora, explicitadas no editorial de lançamento da revista:

A função do Exército num país como o Brasil não é somente o primeiro fator de transformação político-social, nem o principal elemento de defesa exterior: ele tem igualmente a função educativa e organizadora a exercer na massa geral dos cidadãos.[...] os interesses dos militares se acham hoje em dia, e em todos os países do mundo, de tal forma entrelaçados aos interesses nacionais, que trabalhar pelo progresso dos meios de defesa de um povo é, senão o melhor, pelo menos um dos melhores meios de servir aos interesses gerais desse povo. [...] o Exército precisa [...] estar aparelhado para a sua função conservadora e estabilizante dos elementos sociais em marcha e preparado para corrigir as perturbações internas tão comuns na vida tumultuária das sociedades que se formam. [...] Um bom exército é uma escola de disciplina 
hierárquica, que prepara para a disciplina social... ${ }^{4}$. (A DEFESA NACIONAL, 1913)

Desde a sua origem, a revista tentou estabelecer um elo entre o papel do militar e a sociedade brasileira (HORTA, 1994). Por essa razão, foi possível fazer um levantamento das características que marcaram as disputas no campo militar que se refletiram no campo educacional.

O tema "educação" esteve constantemente em foco na revista A Defesa Nacional. É possível, porém, verificar tendências diferenciadas no decorrer de suas publicações. Vale ressaltar, que apesar da educação aparecer, por vezes, secundarizada nos artigos, não diminuía a sua importância, principalmente, pela ênfase dada a função regularizadora e moral que ela proporciona à sociedade e, em especial para o campo militar. Assim, para organizar a análise, os períodos foram balizados por fatos importantes para o campo militar (1922, o tenentismo; 1935, a "Intentona Comunista"; 1945, fim do Estado Novo) que influenciaram os temas abordados na publicação, e foram assim divididos: i) Período de estruturação da revista (1913-1922); ii) Período de transição (1923-1935); iii) período de profissionalização (1936-1945) .

A análise dos três momentos demonstra uma clara transição de um discurso mais social para um discurso mais conservador, ou seja, referente a assuntos militares. A questão social foi perdendo destaque e os problemas endógenos ao campo se sobressaíram. Isso se evidencia na análise feita em relação ao número de publicações produzidas com temas educacionais ao longo desse período. Em que pese a diferença do número de revistas e de tempo entre os dois primeiros períodos, temos uma média mantida em torno de $45 \%$ de artigos. Já no último período analisado a queda em relação ao tema educação é brutal, de $43,3 \%$ para $25,6 \%$. Fato esse que comprova que a partir de 1936 a revista entrou numa fase mais interna ao campo.

\section{Período de Estruturação da Revista}

No primeiro período da Revista, os elementos de disputa no campo militar não se apresentavam em oposição. Tanto o grupo herdeiro do processo de Proclamação da República e de Benjamin Constant, quanto o grupo dos "jovens turcos" convergiam sobre a ideia do cidadão-soldado ${ }^{5}$. O ponto de divergência, mas que mesmo assim não chegava a marcar uma ruptura entre eles, era a questão da profissionalização do Exército. $\mathrm{O}$ Positivismo dos herdeiros de Benjamin Constant os impulsionava a acreditar que uma sociedade militarizada dispensaria a existência de forças armadas, já que o habitus militar estaria difundido pela sociedade. A tese da profissionalização, ao contrário, fortaleceria o campo militar, pois criaria um habitus próprio ao campo, não diluído pela sociedade. Isso não significava uma oposição entre os grupos como afirma Horta (1995, p. 12), ao analisar a Revista A Defesa Nacional: "Os editoriais da revista rejeitam sistematicamente a ideologia do cidadão-soldado". Muito menos os jovens turcos se opunham a Liga de Defesa Nacional, como também afirma Horta (1995, p.12), ao analisar a mesma revista: "[...] os jovens turcos tinham uma concepção de defesa nacional que nada tinham em comum a de Bilac".

Entendo, diferentemente de Horta (1995), que a tese da profissionalização militar diverge somente em alguns pontos da tese do cidadão-soldado dos benjaminianos e da Liga de Defesa Nacional, ou seja, uma não exclui a outra; a preocupação dos jovens turcos, era que, além da formação do cidadão-soldado, se desenvolvesse um habitus militar que 
garantisse a autonomização do campo. Além disso, os pontos de convergência entre os elementos do campo eram maiores e mais visíveis do que os de divergência. Esses seriam: o civismo, o moralismo, o nacionalismo e a educação como fundamento da Defesa Nacional. Ambos os grupos defendiam também, abertamente, o Serviço Militar Obrigatório e a Instrução Primária Obrigatória.

O que se pode perceber pela análise dos artigos é que o tema cidadão-soldado estava presente dentro da revista. Isso demonstra que não existia animosidade entre os grupos, o que confirma o meu argumento de que a ideia de profissionalização defendida pelos "jovens turcos" não divergia da proposta do cidadão-soldado. Passo agora a analisar como os principais temas se desenvolveram dentro da revista nessa fase.

No editorial da revista publicada em 10 de setembro de 1914, a ideia da defesa da Instrução Primária Obrigatória era bastante evidente:

Como forma de guiar a infância para a escola é ensinando-lhes a glória de nossos antepassados conquistada na paz e na guerra, despertando nela o orgulho da nacionalidade. Cultivemos-lhe os músculos com a ginástica e lhes daremos, assim, audácia e confiança. [...] Isso só é possível com a obrigatoriedade da Instrução Primária. (A DEFESA NACIONAL, 1914)

No ano de 1914, então, muitos artigos trataram da relação entre o serviço militar e a instrução pública de qualidade. Importantes figuras do campo militar e algumas com atuação no campo político, como, por exemplo, o general Caetano de Farias, se manifestaram sobre o assunto através da revista. Vale destacar que, ainda em 1914, o $2^{\circ}$ tenente Paula Cidade escreveu um importante artigo, com grandes repercussões no campo militar chamado de Colégios Militares, em que ele propunha a substituição do método teórico das escolas militares por escolas práticas, seguindo o modelo prussiano. Na última revista de 1914, no editorial assinado por Bertholdo Klinger, havia uma intensa análise traçando um paralelo entre o serviço militar obrigatório e a melhoria do ensino no país.

No ano de 1915, os temas permaneceram os mesmos. Destaque para o artigo escrito pelo major Seid em outubro, intitulado $O$ combate ao analfabetismo é um dever de honra do oficial brasileiro, cujo teor criava uma polêmica com relação ao papel dos oficiais na sociedade. Segundo esse, era fundamental a defesa da educação como garantia moral e como forma de engendrar socialmente o nacionalismo no povo brasileiro. Muitos oficiais se sentiram feridos por esse artigo e argumentaram que o papel do oficial não poderia ser reduzido ao papel secundário exercido pelo professor na sociedade brasileira.

Destaco também o artigo escrito pelo major Brazilio Taborda em dezembro de 1915, que defendia a criação de uma escola para oficiais superiores, não só para preparálos à guerra, mas também para os problemas nacionais. É possível verificar nesse texto a defesa de alguns elementos que posteriormente serão caros para as Forças Armadas brasileiras, como, por exemplo, a discussão da importância da defesa e do interesse nacional.

No editorial de janeiro e de maio de 1916, fica evidenciada uma mudança de postura na direção de um discurso mais incisivo. Seu conteúdo defende "o discernimento patriótico [que] só pode ser dado por uma educação cívica bem orientada e bastante difundida, que venha sendo ministrada desde o seio materno até as instituições de defesa nacional" (A Defesa Nacional, 10/01/1916). Nota-se que os editoriais defendem a educação cívica do povo e a necessidade de um modelo de moral desde a mais tenra infância. A escola brasileira deveria seguir os passos dos Estados Unidos e da Argentina "que fundem, no caudilho das escolas, uma liga homogênea, a nacionalidade em formação" (A Defesa Nacional, 10/05/1916). 
Em janeiro de 1917, o editorial analisa o problema do sorteio militar e uma das causas é atribuída à deficiente educação cívica do povo, principalmente das classes contaminadas pelo "bacharelismo malabarista". Além disso, alegava-se que o povo brasileiro não havia sido educado para o sorteio militar obrigatório ${ }^{6}$, que sempre vive como parasita do suor escravo, e que o governo, ao invés de cruzar os braços, deveria estabelecer a obrigatoriedade do ensino primário teórico e cívico e do ensino profissional.

Ainda em 1917, havia uma constante discussão acerca da responsabilidade permanente do Estado-Maior no ensino militar baseado nos seguintes pontos: proposta de criação de uma doutrina sobre o ensino; militares preocupados com a educação dos pobres como forma de garantia da defesa nacional; proposta de reformas da instrução primária e ruptura com a educação coletiva; educação individualizada como na caserna e o desenvolvimento do sentimento patriótico. Segue-se que seria "dever do Estado encaminhar a geração nova a pensar livremente e incutir-lhe um patriotismo sem limites" (A Defesa Nacional, 1917).

Em 1918, o grande destaque foi o artigo do $2^{\circ}$ tenente José Faustino Filho, $O$ ensino primário na caserna, que defendeu a obrigatoriedade do ensino primário na caserna com sua consequente descentralização: "Ambicione o Exército a glória para si de desejar que todo aquele, que regresse à vida civil esteja em condições de vir a ser um verdadeiro cidadão-soldado" (A Defesa Nacional, 10/07/1918).

O ano de 1919 foi significativo para a revista e para a composição do campo militar. Houve nesse momento um fato que estimulou ainda mais a autonomização desse campo. Os editores da revista produzem um artigo intitulado "Os Novos Instrutores da Escola Militar". Esse artigo ressaltou, pela primeira vez, a intervenção do Estado-Maior na escolha de instrutores para as escolas militares, o que demonstra a autonomização e a definição do campo militar.

Ainda no ano de 1919, houve importantes textos que versavam acerca da questão educacional. No editorial de fevereiro, com o título "Questão do momento e Questão do Futuro", abordou-se a questão da educação do povo como fundamental para a definição do futuro da nação. Além disso, o major Pantaleão Pessoa escreveu um artigo que comparava a Escola Militar ao Colégio Pedro II, e, ao final do texto, propôs um curso de aperfeiçoamento para oficiais. Trata-se de um evidente discurso em defesa de um ensino superior militar. Esse artigo fez também a defesa da escola regular como preparatória para a Escola Militar. O autor considerava ofensivo para o oficial alfabetizar uma criança ou um adulto.

Existiu ainda, ao longo do segundo semestre de 1919, uma argumentação de que a administração militar, modificada em 26 de julho de 1919, abordou três grandes problemas: transformar a Escola Militar; incentivar a vinda de uma Missão Militar Estrangeira e o desenvolvimento dos quadros de oficiais. Houve uma defesa do exame vestibular e do fim dos decretos. Viu-se nas primeiras provas do ensino teórico a falta de preparo - mas isso, disse o editorial, já era de se esperar - e uma crítica às falas que apontavam que isso se deu por conta do ensino prático que prejudicava a cultura intelectual dos futuros oficiais.

Em 1920, enfatizou-se que o sorteio do serviço militar beneficiou a educação física dos soldados na difusão da higiene, no combate ao analfabetismo, no ensino ao amor à pátria e na difusão do ensino primário para preparar o indivíduo comum. Havia uma argumentação sobre o que ainda faltava no Exército, como, por exemplo: uma escola de aperfeiçoamento para graduados. Enfatizou-se também, que o ensino de analfabetos (soldados) que a princípio estava a cargo do oficial professor da escola regimental, passou em primeiro de agosto a ser ministrada por professores públicos do Estado de São Paulo, o 
que facilitou a missão dos oficiais. E que os resultados dos soldados nos exames foram animadores. Nota-se ainda a força da tese do cidadão-soldado.

O editorial de março de 1921 criticou a campanha anti-militar na sociedade brasileira: "A pandemia de insubmissão ao serviço militar é o veículo de propagação crítica a educação viciosa do povo brasileiro e os meios de comunicação que fraquejam o entusiasmo cívico" (A Defesa Nacional, 10/03/1921). Além disso, relacionou o serviço militar obrigatório com a instrução primária obrigatória, fundamental para acabar com qualquer manifestação de "baderna" social.

É importante ressaltar ainda que, em 1921, Pantaleão Pessoa se afasta da redação da revista para assumir a direção da Escola Militar, entrando em seu lugar o capitão Eurico Gaspar Dutra, futuro Ministro da Guerra e presidente da Republica. O texto que mais se destaca em setembro de 1921 foi escrito pelo major Leitão de Carvalho, Escola Técnica, no qual seu autor defendeu a criação de uma Escola Técnica para ensinamentos de Artilharia e Engenharia. Em novembro, apareceu o primeiro texto de Dutra tratando, coincidentemente, de educação. O Título era $O$ Ensino Militar, e o que se criticava era o ensino obsoleto da escola, voltada somente para a realidade militar. $\mathrm{O}$ artigo pleiteava também uma reforma para que o ensino aproveitasse ao máximo os ensinamentos da Missão Militar Francesa (M.M.F.); nesse artigo, havia uma forte crítica à educação brasileira por excesso de bacharéis e elitismo.

Para finalizar esse primeiro período, é importante destacar que o ano de 1922 foi muito complicado para a revista por conta dos "distúrbios" sociais (o levante do Forte de Copacabana, a criação do Partido Comunista e a revolta dos tenentes). Principalmente para os militares, isso se reflete na mudança que a revista sofreu nos anos seguintes.

\section{Período de Transição}

No segundo período (1923/1935), começaram as disputas mais acirradas dentro do campo militar. Novas realidades se impuseram ao campo, como, por exemplo, o Tenentismo, a Coluna Prestes e os Militares Comunistas. O campo militar torna-se mais complexo: houve uma fusão de interesses entre os jovens turcos e os herdeiros de Benjamin Constant. Ao mesmo tempo, houve a ascensão de um grupo conservador religioso militar: a União Católica Militar (UCM).

Por conta das novas realidades acima mencionadas, foi possível verificar nas edições da revista $A$ Defesa Nacional o aparecimento de novos temas que anteriormente não foram cogitados, são eles: o discurso da laicidade, o discurso religioso, a regeneração moral e a educação moral e cívica

Nota-se uma diminuição de artigos com os temas de cidadão-soldado e de profissionalização, o que demonstra que esses temas não eram mais tão prioritários, comprovando a tese da fusão de seus interesses.

Esse período foi marcado também por uma grande variedade de redatores que substituíram os originais: Nilo Val, Eurico Dutra, Francisco José Pinto, Artur José Pamphiro, Paes de Andrade, Sebastião Scheleder, Mario Travassos, Jorge Duarte, Renato Batista Magalhães, Arthur Chave, Humberto Castelo Branco, Fernando Saboya, Tristão Alencar Araripe, A. Bellagamba, H. Bustamante, Castro e Silva, Leitão de Carvalho, Aljamar Mascarenhas e Baptista Gonçalves.

O primeiro destaque a ser feito é o artigo do major Engenheiro Amílcar Botelho de Magalhães, portanto um retorno da família Botelho de Magalhães ao cenário militar, $A$ crise dos técnicos e o Ensino Militar, de 1923, apontou para a necessidade de se refletir sobre a formação técnica dos oficiais. 
A defesa da organização nacional militar como forma de defesa da nação foi um ponto marcante no período, para isso necessitava-se de uma reforma que atendesse os serviços básicos de educação e saúde. Ressalto também, em 1923, o texto do capitão Paula Cidade, defendendo a formação militar sem isolar o aluno do mundo e a formação para a cidadania. A tese do cidadão-soldado ainda estava viva. "A Defesa Nacional não se tem cansado de bater periodicamente nesse ponto vital para o Exército e para a nação".

No final de 1923, surgiu uma novidade na revista: a preocupação com a legislação militar. Mais um elemento de identificação e autonomização do campo. Foi publicada também nessa revista uma lista de soldados analfabetos que seriam alfabetizados pelo Exército.

O editorial da primeira revista de $1924 \mathrm{fez}$ uma defesa da mudança da capital para o planalto central. Curiosamente, fez referência a Alberto Torres, conhecido inimigo da campanha do Serviço Militar Obrigatório. Em junho desse ano o editorial fez uma extensa defesa da M.M.F.

O mais importante destaque a ser feito em 1924 é o editorial de setembro, cuja defesa da industrialização da sociedade como desenvolvimento do fator moral era incontestável, a partir da defesa de um ensino de cultura cívica e moral. Nesse momento, começam a aparecer elementos difusos do positivismo com mais intensidade. Houve um crescimento do discurso da moralidade. Mais uma vez, o ensino apareceu como difusor da tese da regeneração moral da sociedade. Um exemplo disso é o editorial de outubro intitulado $O$ Ensino Primário Obrigatório.

Não se pode deixar de destacar nesse período o intenso discurso sobre a necessidade do Exército de criar um órgão que pensasse a doutrina militar. No editorial Quadro e Cursos Técnicos (A Defesa Nacional,10/2/1924), houve uma defesa da formação de quadros técnicos no Exército.

As primeiras revistas de 1925 faziam uma crítica à preparação dos engenheiros militares, por eles adquirirem compreensão com igual importância entre a parte técnica e militar. As publicações enfatizavam que os oficiais engenheiros só recebiam instrução militar igual a dos oficias que se destinavam às outras armas, ou seja, os engenheiros militares não construíam conhecimentos militares que em campanha lhes seriam exigidos referentes a suas especificidades.

Em 1926, o destaque foi para o aumento do interesse interno ao campo militar e sua relação com a sociedade. A proposta era defender o campo e expandir as suas conquistas. No editorial de maio e junho "O que fizemos - O que nos resta fazer", foi feita uma análise das conquistas e do modelo de organização das instituições militares. O que faltava, na avaliação do campo, era lançar as bases da organização militar da nação. Acabar com a idéia de que o Exército pretendia transformar a sociedade num imenso quartel. Era o início da fusão com a tese do cidadão-soldado e a constatação que chegava a hora de o Exército participar de forma mais efetiva na vida nacional: "A luta pela consciência da defesa nacional é obrigação do Exército e Armada, para isso é necessário uma educação eficiente para a evolução moral e cívica da nação" (Magalhães J. B, artigo A propósito da situação militar de 10/06/1926).

Em julho de 1926, no editorial com o título Deve-se educar o Espírito Militar da Nação, defendeu-se a necessidade de um esforço militar para educar uma mentalidade militar nos civis; "O Oficial brasileiro deve ser o sacerdote severo e convicto da ressurreição nacional” (A Defesa Nacional, 10/06/1926). Nesse momento, começam a aparecer sinais do discurso religioso. Nesse mesmo mês, um artigo polêmico do capitão Benjamim Ribeiro, A criação de hábitos morais pelo Exército, defendia que o hábito moral militar é superior e deve servir de exemplo para a sociedade. 
O major Agrícola Bethlem, em artigo (A Defesa Nacional,10/09/1926) intitulado Educação, acreditava que o principal objetivo dos militares era propor mudanças no ensino secundário que permitissem formar a mentalidade de nosso povo, para concorrer à formação da raça brasileira. Para se ter uma nação deve-se ter uma educação eficiente. $O$ autor fez a seguinte proposta dividida em três aspectos: Educação Física, Educação Intelectual e Educação Moral.

As últimas revistas de 1926 exaltaram a Escola Militar, agora dirigida por um exredator de A Defesa Nacional, Pantaleão Pessoa. Nesse momento, a revista expôs um conjunto de informações sobre as melhorias que as últimas direções fizeram na Escola Militar. Destaque para o artigo do capitão João Marcelino, A Escola Militar, no qual seu autor declarou que "a escola militar era a responsável por moldar em seus alunos a nacionalidade brasileira, transmitir-lhes a vibração constante de seus corações, ávidos das glórias que a carreira encerra" (A Defesa Nacional, 10/12/1926).

No ano de 1927, em julho, houve uma fusão das revistas A Defesa Nacional e $A$ Bandeira, revista militar paulista. A revista passa, então, a apresentar um caráter mais vanguardista. Defendia que a população deve ser preocupada com a defesa e a formação nacional, ou seja, a questão da educação. No número de julho há um anexo da Associação Brasileira de Educação (ABE), que indicava cursos que deveriam ser feitos por militares.

O artigo do $1^{\circ}$ tenente Bellagamba de outubro 1927, Um projeto contra o analfabetismo e o Exército, analisa o projeto de lei apresentado na Câmara para acabar com o analfabetismo. A preocupação com o quartel-escola e oficiais-professores mostra mais uma vez a fusão com o discurso do cidadão-soldado.

Em 1928, o grande destaque foi a tentativa de estancar o crescimento religioso nas Forças Armadas, mais especificamente, do catolicismo. Na diretiva de atuação de A Defesa Nacional, aprovada em Assembléia Geral do grupo mantenedor, em 3 de outubro de 1928, lê-se o seguinte: "Ser independente do credo religioso ou filosófico, bem como doutrina política, não vinculando idéias de propaganda ou combate a credos ou doutrina que tais ...”.

O artigo A Missão do Oficial e o seu prestígio na sociedade (texto sem autor), de novembro de 1928, enfatizou que a função de educador social seria do oficial do Exército, principalmente, pelo seu valor moral indiscutível e por seu status impor respeito, o que só ocorre por incompetência dos professores tradicionais.

Em dezembro de 1928, houve uma mudança no regimento da revista. A partir desse momento, o grupo mantenedor teve um representante naval (Mena Barreto) e um representante civil - Frederico Duarte - (Colégio Militar). Houve também nesse exemplar um duro discurso em favor do serviço militar obrigatório e do ensino primário obrigatório.

No artigo, O problema da Educação Física Nacional, o capitão Tristão Alencar Araripe enfatizou que no passado muita gente apenas enxergava a alfabetização ou, quando muito, a formação dos sentimentos morais e cívicos do homem brasileiro. Alegou também que esta noção restrita do assunto, mesmo nos meios cultos, em que o problema vinha sendo ventilado com carinho, firmeza e patriotismo, também aconteceu nos congressos de Educação realizados no Brasil. Fez ligeira exceção à $\mathrm{ABE}$, onde havia uma comissão encarregada da Educação Física e da Higiene.

Só a Educação Física, de mãos dadas com a higiene, é capaz de transformar-nos em raça verdadeiramente forte, com saúde, vigor, destreza e virilidade; somente ela poderá criar e multiplicar o bandeirante ousado, desbravador de nossos sertões despovoados, explorador destemido de todas as energias que latentes existem no seio da terra. A 
Educação Física constitui alicerce do engrandecimento nacional (A DEFESA NACIONAL, 10/12/1928).

Em fevereiro de 1929, sai publicado como encarte da Revista o primeiro número de uma publicação do órgão da União Católica Militar (UCM). Seu diretor era Jorge Pinheiro $(\mathrm{CM})$ e subdiretor o $1^{\circ}$ tenente Floriano de Menezes. O Centurião, órgão da UCM, era destinado a difundir a instrução religiosa e cívica entre os soldados do Exército, da Marinha e de todas as Corporações Militares do país.

A nossa religião não quer a fé que não seja fundamentada em boas obras; que todos os Católicos sejam assinantes, sejam propagadores de nosso jornal, que se propõe a ser a alma da nossa obra. [...] Avante, pois Católicos Militares, mandai-nos desde já a relação dos assinantes que conseguistes. (O CENTURIÃO, In; A DEFESA NACIONAL, $10 / 02 / 1929)$

Em Março de 1929, os redatores da revista A Defesa Nacional publicam artigo sobre a Lei de Ensino Militar que afetava diretamente os militares:

A reforma de ensino que ora se opera manifesta o início de uma fase nova, verdadeiramente reconstrutora. Claro que essa reforma há de encontrar fortíssimas oposições, resistências passivas e ativas a vencer. [...] Há em jogo dois interesses: de um lado os interesses legítimos do Exército e de outro os interesses individuais onde o comodismo e a alta de vontade de efetuar esforços novos tomam vultos dominantes.[...] Essa nova lei fortalecerá o organismo do Exército em direção a um progresso real, metódico e contínuo libertando-o de uma mentalidade inadequada, inculta e sem vivacidade (A DEFESA NACIONAL, 10/03/1929).

Assim, o ano de 1929 foi todo marcado pela discussão acerca da nova lei de ensino militar e de questões relativas a problemas específicos desse ensino, como: a qualidade dos professores das Escolas Militares, o tipo de ensino e, até mesmo, um local mais adequado para o funcionamento dessa Escola.

A década de 1930 marca o início da discussão sobre a ideia de Segurança Nacional. Essa proposta surgiu em contraposição à tradicional tese da Defesa Nacional, postulada por décadas pelas Forças Armadas. No bojo dessas discussões, nascia a proposta de criação de uma Instituição que pensasse a Segurança Nacional. A princípio, essa instituição seria o Estado-Maior das Forças Armadas; posteriormente, os militares passaram a entender que era necessário um lugar de formação de quadros de inteligência que pudessem orientar para os novos objetivos das Forças Armadas. Esse posicionamento aproximou mais ainda o campo militar do campo educacional, já que ficava evidente para os militares que, se não ocorresse uma mudança na educação do Brasil, a questão da Segurança Nacional ficava enfraquecida.

Entretanto, o ano de 1930 foi marcado por grave crise no Estado brasileiro, a saber: os reflexos da crise econômica de 1929; a ruptura da Política do Café com Leite com a eleição de Julio Prestes e a pressão de novas forças políticas que ascendiam no cenário nacional, entre elas, os militares. A revista apresentou textos coerentes com o período, basicamente ligados à questão da defesa nacional. Essa era uma discussão recorrente em situações de crise, principalmente, quando a crise apresenta âmbito internacional, como era o caso desse momento. 
Outra característica interessante da revista nesse ano era a tentativa de se estabelecer discussões efetivas com relação a problemas específicos do campo militar. A questão referente ao tema das promoções militares esteve presente em todas as revistas do ano de 1930. Por exemplo, no artigo "Lei de Promoções de Oficiais", escrito em fevereiro pelo coronel Bertholdo Klinger, a proposta de promoção por escolarização começou a ganhar força.

Ainda sobre o ano de 1930, não se pode deixar de mencionar os artigos e editoriais que trataram da reorganização das Forças Armadas a partir da criação de novas escolas para oficiais. Em editorial, de abril desse ano, assinado pelo major Humberto Castello Branco (futuro Presidente da República), existia uma defesa da criação de escolas específicas para se repensar a reorganização do Estado Maior do Exército. Ele propôs a elaboração de uma Escola Superior de Guerra com esse intuito.

Havia também nessa década um discurso otimista, justificado pelo papel que o campo militar passou a ter no processo que culminou na revolução de 1930. Em editorial de maio desse ano, mais uma vez escrito pelo major Humberto Castello Branco, havia uma defesa otimista dos avanços na sociedade brasileira, segundo o qual "apesar dos pesares, a campanha educacional tem sido intensa, sem esmorecimento e com êxito satisfatório no campo da regeneração do sentimento cívico, da cultura física e do aperfeiçoamento intelectual" (A Defesa Nacional, 10/05/1930). Em julho do referido ano, em nota dos redatores com o título de Alerta! É preciso educar o homem, a revista apresenta o seguinte texto:

[...] a necessidade de se educar o povo moralmente, pois o perigo que nos ameaça é de tal monta que não há tempo a perder para armar uma cruzada salvadora pela educação Moral - Educação Moral do povo e Educação Moral do soldado. A primeira constitui principalmente tarefa da imprensa e da escola que nela devem empenhar-se com ardor e sem regatear esforços. Ela reclama o aparecimento de um novo Bilac, evangelizador vibrante do patriotismo sem restrições. A segunda é obra de todos nós e para qual nós devemos voltar numa intensificação de esforços sem limites, crentes de que trabalhamos a salvação da Pátria e da Família (A DEFESA NACIONAL, 10/07/1930).

O ano de 1931 trouxe uma novidade: o aparecimento do major Góes Monteiro como redator da revista, já que, nesse ano, principalmente no seu primeiro bimestre, o Brasil ainda sofria os vestígios da crise política do final de 1930. O primeiro número da revista só foi lançado em março, e as Escolas Militares só reabriram em 15 de abril. Depois voltaram a funcionar as Escolas de Estado-Maior, de Aperfeiçoamento de Oficiais de Cavalaria, de Intendência, de Saúde, de Veterinária e a Militar de Realengo. A escola de sargentos já estava funcionando desde o início do referido ano.

Já o ano de 1932 foi muito complicado para a revista, pois um dos seus principais nomes e um dos criadores da revista, Bertholdo Klinger, se colocou contrário ao governo na Revolta Constitucionalista de São Paulo. Esse fato gerou uma crise na revista que a manteve fechada por seis meses. É importante destacar que a revista recebeu uma nova cara nos anos que se seguem, assumindo, pelo menos até 1935, um caráter bastante contraditório, às vezes avançado e às vezes conservador para a época. No editorial dos números 227 e 228 de abril de maio de 1933, publicado juntos pelo novo corpo editorial da revista, a saber: coronel Castro e Silva, major João Batista Magalhães, capitão Renato Nunes, capitão Alexandre Chaves, $1^{\circ}$ tenente José Faustino Filho e $1^{\circ}$ tenente Batista de 
Matos, havia um texto intitulado A Propósito do Momento atual, cujo conteúdo fazia um resumo da História do Brasil:

[...] firmando um programa de aspirações mínimas congregando arregimentando em torno de idéias capitais de ordem todos quantos não são destruidores da civilização, tenderam a reconstruir, de fato, os católicos o sentimento nacional brasileiro. Que correntes ou partidos políticos não inscreveram em seus programas as aspirações da nova e poderosa corrente eleitoral que se formou no Brasil inteiro, sob uma autoridade hierárquica única, independentemente das influências provincianas.[...] O disciplinado espírito católico regido pela formidável hierarquia canônica que há quatro séculos vem contribuindo para a formação de um Brasil uno [...] serviu para reajustar os laços de solidariedade nacional entre os 45.000 .000 que habitam em 1933. [...] É a aceitação de um dogma, guiando, coordenando os pensamentos, contendo as tendências isoladas e dando valor aos atos individuais pelo fato de mantê-los todos convergentes. Devemos ao espírito e à organização católica os serviços que incontestalmente acabam de prestar à Pátria, contribuindo mais uma vez para a sua unificação (A DEFESA NACIONAL, 1933, p. 167).

Em seguida, a revista assumiu que apesar do bem que o catolicismo prestou no momento, poderia não ser o meio próprio e único para "manter e desenvolver o espírito de solidariedade nacional na senda do progresso, sem graves perturbações, processo apenas acompanhado a golpes de inteligência e de habilidade de seu sacerdócio" (A Defesa Nacional, 1933, p. 167). Nesse momento, ficava claro que ocorria uma estranha fusão de pontos de vista que até então viviam separados no campo militar: o Positivismo "benjaminiano" e o Catolicismo.

De fato a grande ruptura da revista se deu em 1935, inclusive o formato da revista mudou. Ela passou a ser dividida em seções, tendo uma seção exclusiva de Pedagogia, assinada pelo capitão João Ribeiro Pinheiro. Esse foi um militar ímpar dentro do campo. E, se ele escrevia na revista, era porque, de alguma maneira, representava a opinião dela. Para entendermos melhor essa seção, vale uma pequena digressão sobre o mencionado capitão.

João Ribeiro Pinheiro era um militar do Exército, lotado no $3^{\circ}$ Grupamento de Infantaria no Rio de Janeiro. Membro ativo da intelectualidade carioca, era Conselheiro da Associação Brasileira de Educação (ABE) e possuía relações pessoais com os principais pensadores da área na capital do Brasil, entre eles: Anísio Teixeira e Fernando de Azevedo. Era leitor do movimento da Educação Nova, citava Dewey e Kilpatrick em seus trabalhos e defendia um ensino transformador, tanto para civis quanto para militares. A sua morte prematura em 1935, durante a "Intentona Comunista", marcou uma radicalização do discurso da revista para o lado conservador. Ganhando força internamente os grupos religiosos, basicamente o Católico. Vejamos alguns dos mais importantes textos do capitão João Ribeiro Pinheiro.

Na revista número 248 de janeiro de 1935, o mencionado capitão escreveu o artigo A Pedagogia Moderna e o Exército, dizia o texto:

O grande movimento educacional após a guerra, oriundo da necessidade de racionalizar a educação, coordenando-as com as finalidades biológicas e sociais, fez nascer uma escola funcional ou ativa. [...] O Exército não pode ser alheio a esse sistema educacional, que ora se organiza no mundo, do que vai depender a mentalidade, quiçá a sorte, das gerações 
vindouras. Ao Exército, mais que qualquer outra organização, pela sua feição deve adaptar os ditames da escola ativa. Não só na caserna, diretamente sobre os soldados, como todos os escalões do seu ensino. É o regime da experiência, que mais convêm a "escola da vida", que é a caserna moderna. Todo o mundo de representações e de elaborações intelectuais se faz sob as bases da experiência e dos atos vividos. Diz Dewey - o grande pedagogo americano (....): Aprender, na forma educativa moderna é ter experiência. A escola é a instituição pela qual a sociedade transmite a sua experiência. A escola é, pois uma sistemática "reconstrução da experiência". E a caserna é tão somente uma escola, uma escola no mais amplo - no mais humano - no mais perfeito sentido.[...] O primeiro passo para estabelecer o "espírito pedagógico" moderno no Exército seria a criação do Departamento de Pesquisas Pedagógicas. Esse órgão seria composto de oficiais que tivessem gosto pelos assuntos pedagógicos e não professores ou oficiais com o curso da E.E. M., obrigatoriamente. A sua primeira fase seria de investigação. Estabelecido um plano - se processaria a experiência nas escolas e nos corpos de tropa. Depois, de assentado o que dava resultado - real - então se faria um plano de ensino, de acordo com o novo sentido pedagógico, aplicando os novos métodos. $\mathrm{O}$ uso do teste, do método de projeto, dos trabalhos manuais - globalização - filmoteca, psicologia objetiva para eliminação do tabu da matemática, que é uma mera aptidão, etc. Levando em conta que o soldado brasileiro tem, em média, uma "idade mental" de doze anos - cumpria aquele Departamento fazer os regulamentos do ensino como cartilhas, pois, é claro, que a cultura do oficial não se pode ater a elas. Passava a guiar o limite de seus ensinamentos pelo Código de Instrução, que deveria ser realizado. [...] Esses regulamentos deveriam obedecer uma forma gráfica didática e serem ilustrados abundantemente, tal como os livros de Cmt. Lafargue ou os regulamentos americanos, de que, oportunamente trataremos aqui.[...] Material e homens nada valem sem instrução. Essa tem que ser transmitida de acordo com o sentido da vida moderna, do contrário é desprezar o avião para andar de carro de boi. (A DEFESA NACIONAL, 10/01/1935)

Era realmente muito clara a relação coerente desse autor com o período ${ }^{7}$. Em março desse ano, o citado capitão escreveu um artigo intitulado $O$ Exército e o Valor Pedagógico do Cinema, em que afirmava que a "memória visual" era a memória mais forte, e através dela a compreensão era fácil e perfeita. Assim, seria de alta conveniência se o Estado Maior do Exército organizasse uma filmoteca de instrução.

Em setembro de 1935, dois artigos se destacaram: o primeiro de João Ribeiro Pinheiro na seção de pedagogia e o segundo do capitão Sebastião Sombra na seção de Estudos Sociais.

O primeiro chamava-se As Universidades e o Exército; tratava-se de uma análise sobre a notícia de que o governo iria criar três novas Universidades: em Minas Gerais, em São Paulo e uma cidade universitária federal. Pondera que:

Não me consta, todavia, que nestes centros de formação de "elites" nacionais, nestes núcleos de futuros chefes e estadistas, tenha havido qualquer infiltração da "política externa do Exército". No entanto, nenhuma oportunidade melhor para conseguir um núcleo de propaganda e irradiação cultural e cívica, através da criação de uma Academia Militar da Reserva. Esta Academia englobaria um curso livre de conferências para professores - um museu - uma biblioteca, além de controlar toda a 
educação física universitária. Indiscutivelmente, as diferentes "questões militares" desde o Império vem separando o Exército da grande massa como um mundo especial, alheio aos anseios e as tradições da nação. Precisamos familiarizar a mocidade intelectual com os nossos problemas, com a nossa vida, com os conhecimentos técnicos da arte militar, a fim de fazê-la sentir a mística do manejo das armas, da organização do Exército, insígnias, atributos e linguagem militar. (A DEFESA NACIONAL 10/09/1935)

No segundo artigo, de Sebastião Sombra, intitulado Noções de Sociologia, ele criticava a disciplina Educação Moral e Cívica. Enfatizava a importância do ensino de sociologia, cadeira que ele ministrava no $1^{\circ}$ ano da Escola Militar e defendia, ao contrário de muitas críticas, que era a Sociologia nessa escola que iria formar moral e intelectualmente o aluno, pois, em adulto, quando fosse para Escola do Estado Maior, o aluno já estaria mais maduro. Não considerava válido reduzir a preparação sociológica do cadete a aulas de Educação Moral e Cívica, pois segundo o autor esta disciplina "não oferece base doutrinária para que o aluno venha a julgar tal regime melhor do que outro" (A Defesa Nacional 10/09/1935).

Em novembro de 1935, portanto o último artigo escrito por João Ribeiro Pinheiro antes da sua morte, tratava-se da questão moral da sociedade. Intitulado Nova Educação Moral, o artigo fez uma alusão ao problema da educação moral, que, segundo ele, encontrava-se nos métodos pedagógicos antigos que trabalhavam pela coação. Alegava que naquele momento o problema de conduta era o mais importante de todos na educação moral. Dizia que a pedagogia moderna devia colocar o indivíduo numa situação tal que tivesse que experimentar diretamente as realidades espirituais, descobrindo, pouco a pouco, por si mesmo, as leis que as regiam.

Em dezembro de 1935, a revista lançou nota lamentando os trágicos acontecimentos ocorridos em novembro daquele ano, bem como a morte de oficiais e soldados, entre eles, o agora então major João Ribeiro Pinheiro.

Com efeito, os acontecimentos de 1935 foram vitais para as mudanças que ocorreram na revista A Defesa Nacional. Não foram, é claro, os únicos responsáveis, pois já desde o início dessa década havia uma mudança no discurso da revista. Todavia, de 1936 até 1945, as mudanças foram muito mais explícitas.

\section{Período de Profissionalização}

No terceiro período (1936-1945) da revista, ocorreu uma mudança conservadora. Por diferentes motivos, as discussões acerca dos problemas sociais diminuíram bastante; a preocupação da revista passou a ser interna ao campo. Isso pode ser explicado tanto pela ditadura do Estado Novo, quanto pela realidade da Segunda Guerra Mundial, que colocou, como ordem do dia, os problemas referentes à questão militar.

Devido a esse caráter endógeno, o discurso sobre a necessidade da escolarização superior de oficiais cresceu bastante. A defesa incondicional da educação como forma de regeneração moral baseada na velha tese positivista também ganhou força. Isso levou a proposta e a efetivação da disciplina Educação Moral e Cívica a entrar no campo educacional. A hegemonia do grupo conservador-religioso que se apropriou desse discurso positivista difuso dentro das Forças Armadas se tornou uma realidade que marcou o campo militar durante toda a segunda metade do século XX, o que pode ser observado na análise das revistas e no aparecimento do tema do anticomunismo, demonstrando a preocupação desse grupo na manutenção dos valores morais. 
Nesse período, a seção de pedagogia sobreviveu até o início da década de 1940, todavia com um caráter bastante diferenciado. Passou a ser assinada pelo major Sebastião Sombra, que deu uma guinada forte para o conservadorismo. Havia ainda um discurso em prol da modernização das práticas pedagógicas nas Forças Armadas. Isso se comprova no artigo de Sombra de fevereiro de 1936, com o título Um Programa Pedagógico, no qual enfatizava-se que "ninguém mais ignora os métodos pedagógicos. Internacional e nacionalmente eles são divulgados e as professorinhas primárias já as usam em suas salas, porém no exército eles ainda não foram incorporados e os professores usam métodos atrasados " (A Defesa Nacional, 10/02/1936).

Sob a redação do major Sombra, a seção de pedagogia ganhou um caráter mais teórico e conservador; seus artigos circulavam a área da Filosofia da Educação. Isso fez com que a discussão, que antes era prática, com o major Pinheiro, desaparecesse.

Outro tema que ganhou força na revista, como já foi dito, foi o anticomunismo. Em abril de 1936, um artigo assinado pelo $1^{\circ}$ tenente Médico Everardo Backeuser com o título O Comunismo e a Educação apresentava nesse momento o inimigo maior das Forças Armadas brasileiras no século XX:

[...] O combate ao comunismo será ineficaz se limitar-se a medidas de repressão policial. [...] a Educação é a melhor meta para esterilização do Comunismo. É a educação que fortalecerá a fé em Deus, o amor a Pátria e o respeito a família,[...] e para isso deve ser restabelecido em todos os estabelecimentos primários, secundários e principalmente nos normais e profissionais o ensino cívico. (A DEFESA NACIONAL, 10/04/1936)

Fica clara também, a mudança de opinião do major Sombra, já que em setembro de 1935, portanto alguns meses antes desse artigo de janeiro de 1936, ele escrevia criticando a Educação Moral e Cívica. Nesse momento, o major passou a entender que a melhor coisa para a sociedade brasileira era a regeneração moral e a constituição de uma disciplina escolar sobre Moral e Civismo. É possível verificar que essa mudança representa o processo de acirramento em que o governo estava entrando e de apoio desse segmento militar ao enrijecimento do regime.

A partir de maio de 1936, a seção de pedagogia se limitou a discutir a criação de um programa educacional para o campo militar e uma atuação frente à proposta de construção de um Plano Nacional de Educação. Em dezembro desse ano, o major escreveu o artigo O Exército e o Plano Nacional de Educação, no qual explicou e demonstrou os princípios do plano, enfatizando que esses princípios sintetizavam o pensamento e a orientação pedagógica cristã e brasileira. Ressalto ainda que, em nota de rodapé, Sombra disse que esses princípios estavam baseados na Filosofia Tomista.

Em 1937, o capitão Souza Junior, em artigo na Seção de Pedagogia, criticou a forma "defeituosa" com que era feito o recrutamento de instrutores para as Escolas Superiores do Exército. Defendeu a criação de um lócus específico para uma melhor formação do oficial em nível superior, no caso, uma Escola Superior de Guerra.

Outra característica interessante do ano de 1937 foram os "alertas": pequenas manchetes no corpo da revista indicando elementos do campo social a que o campo militar deveria ficar atento. Esses textos buscavam alertar a sociedade contra um mal que vinha corroendo as bases "morais" da família e da pátria. Indiretamente, a questão era o comunismo.

No editorial de junho de 1937, havia uma epígrafe com o seguinte dizer: "Não há educação sem respeito, respeito sem autoridade, autoridade sem preceito". O texto foi escrito pelo tenente coronel Tristão Alencar Araripe, e versava sobre o recrutamento para o 
oficialato, além de conclamar a categoria a pensar em propostas para o ingresso dos oficiais nas Forças Armadas e defender o concurso público.

Em 1937, a edição das revistas ficou bastante comprometida por razões do contexto político interno. Um novo grupo de redatores assumiu a revista, controlado pelo coronel Tristão de Alencar Araripe. Além dele, apareceu Alcides de Mendonça Lima Filho, Aluízio Mendes e Armando Batista Gonçalves, todos majores do Exército.

A partir de janeiro de 1938, a revista assumiu um caráter pró-governo. Tanto que no primeiro número desse ano, no editorial, havia uma transcrição de um discurso de Vargas defendendo a valorização das Forças Armadas, preparação em caso de guerra. Havia também uma transcrição de uma palestra feita pelo Ten. Cel. Juarez Távora na Escola Politécnica do Rio, defendendo a criação de uma Escola Superior de Guerra. A revista ficou suspensa de julho a dezembro de 1938, ou seja, não foram editados os números 278 , 279, 280, 281, 282 e 283.

Em fevereiro de 1938, a questão doutrinária das Forças Armadas ganha muita força, endossando a tese de uma política efetiva de formação de oficiais. O $1^{\circ}$ tenente Murilo Borges Moreira propôs um método pedagógico e doutrinário com que se deveria abordar qualquer questão de instrução.

O possível cenário de guerra passou a ser tema constante a partir de março de 1938. Freqüentes análises conjunturais eram feitas, tanto nacional quanto internacionalmente, e havia uma valorização dos novos instrumentos de propaganda social. O capitão Leonardo Ribeiro Filho escreveu sobre a importância do cinema e sua relação com o serviço de instrução. No final do ano, em outubro, o capitão Aluízio de M. Mendes escreveu um texto denunciando o alto índice de analfabetismo.

A partir de 1939, a revista intensificou a discussão acerca dos problemas do campo militar, atentando para a grande guerra que se apresentava de maneira inevitável. A discussão da educação aparecia agora no contexto da segurança nacional. Esse termo começou a ser desenvolvido no campo militar e, em breve, substituiria o conceito de defesa nacional. Uma prática que aumentou muito também a partir de 1939 foram as transcrições de palestras e textos de jornais. Isso se justificava pela intensa mobilização militar em torno da guerra, o que dificultava a produção intelectual militar. Um exemplo disso foi a transcrição da conferência Educação e Segurança Nacional, ministrada por Lourenço Filho na Escola de Estado Maior do Exército em outubro de 1939 e publicada em novembro na revista A Defesa Nacional.

Nessa conferência, a Educação era encarada de modo objetivo e aparecia como um dos processos pelos quais as sociedades experimentavam a sua capacidade de vida através do tempo. Da mesma forma, a nação e a nacionalidade eram produtos históricos, e mais recentes até do que vulgarmente se imagina: "Desprezar a gênese das instituições, que as expliquem, será dificultar a compreensão de suas funções próprias e das relações que apresentam com o processo educativo" (A Defesa Nacional, 1939).

Em 1940, a discussão da revista era referente ao campo militar e à necessidade de o Brasil de se preparar para um possível ataque. Nesse contexto, o que mais se destacou de análise do campo social foi a importância dada a Psicologia. Destaque para o artigo do $1^{\circ}$ tenente Moacyr Ribeiro Coelho. Segundo esse, o estudo dessa ciência fornece métodos racionais e produtivos para o melhor desempenho das funções militares.

O ano de 1942 foi marcado pela declaração de guerra do governo brasileiro ao eixo e pelos preparativos de guerra. Apesar de o Brasil só ter mandado a sua primeira tropa em 1944, desde 1942 já se encontrava em estado de guerra.

$\mathrm{Na}$ revista, houve nova mudança de redatores, a saber: general Heitor Augusto Borges, coronel Orozimbo Pereira, tenente coronel Lima Figueiredo, tenente coronel 
Djalma Ribeiro e major Armando Batista Gonçalves. No editorial da revista de março de 1942, já estava clara a intenção de mobilizar a sociedade, principalmente a juventude, com práticas semelhantes à militar,

[...] nenhum problema nacional supera o da organização da juventude em importância e premência. Mas também nenhum tão delicado e difícil. O que fazermos com a juventude hoje será o crédito do Brasil de amanhã. [...] Agora mesmo o governo estabeleceu a instrução pré-militar dos escolares, o que representa um passo gigante na arregimentação física da mocidade. Queremos chamar, todavia, a atenção para o escotismo. [...] O escotismo nasceu do arguto espírito de Baden Powel, militar e educador, feliz associação que explica em boa parte o equilíbrio do seu sistema. (A DEFESA NACIONAL, 10/03/1942)

Em junho de 1942, o coronel Valmir Ramos escreveu o seguinte artigo: Notas do meu caderno: Os velhos também têm idéias novas. Tal artigo enfatizava a importância das gerações antigas sobre as novas, texto com forte conotação positivista, sem, no entanto, mencioná-la. Outro artigo do mesmo mês do capitão Nelson Rodrigues de Carvalho, que também apresentou forte influência positivista, chamava-se Oficial Regimental de Educação Moral, no qual se destacava a moral como o mais poderoso fator de sucesso.

De setembro a novembro de 1942, a revista se dedicou à guerra e à exaltação do Estado Novo. Destaque para a declaração do Ministro da Guerra (Dutra), conclamando unidade militar e social após ataque nazista a navios brasileiros. Outro destaque foi o editorial de novembro de 1942, exaltando o Estado Novo criado em 19 de novembro de 1937. Esse foi um período de forte defesa do nacionalismo e das obrigações cívicas para enfrentar a guerra.

No editorial de dezembro de 1942, havia uma forte crítica à "Intentona Comunista" de 1935 e à revolta Integralista de 1938. Era uma forte exaltação a Deus e à família como responsáveis pela manutenção da ordem no Brasil. A partir do ano de 1943, a revista assumiu um caráter bastante religioso. Começaram a ser publicados os artigos do coronel, posteriormente general, Silveira de Melo, sobre temas religiosos, associando-os aos temas militares. Essas características religiosas não deixaram mais a revista nesse período.

Apresento agora alguns destaques do ano de 1943 acerca da aproximação do campo militar sobre o campo educacional. Em primeiro lugar estava o artigo Escola de Comando - destinado a preparação de oficiais do Estado Maior, publicado em agosto, que defendia uma melhor preparação dos oficiais brasileiros e a criação de uma Escola Superior de Guerra. Em segundo lugar, o artigo de novembro de 1943, traduzido pelo capitão Nelson de Carvalho, A última década da História do Brasil, por Percy Alvin Martin, que fez uma análise histórica das ultimas décadas da história do Brasil, no caso os anos de 1920 e 1930. Por fim, o editorial de dezembro de 1943, que fez referência e teve como base a obra de Fernando de Azevedo: A Cultura Brasileira. O texto aponta que o autor dessa grandiosa obra analisou a progressão do ensino militar no Brasil em três momentos, a saber: 1- A criação da Escola de Estado Maior (1874-1905); 2- Influência da Missão Militar Francesa (1905 a 1930); 3- O período da cientificidade do Exército (1930 em diante). O editorial destacou também o investimento feito pelo Exército na criação de novas Escolas Militares, principalmente, a de Resende.

O texto mais importante do ano de 1944 foi publicado em maio, Como orientar a juventude, escrito pelo major Xavier Leal, afirmava que em todos os países, em todos os tempos, a juventude sempre constituiu o futuro, a esperança da nacionalidade. 
[...] Os moços que compõem a juventude de hoje, devendo ser os homens de amanha, aqueles que irão assumir os postos de responsabilidade e dirigir os destinos da nação, passando, intermediariamente, por outros postos ou desempenhando obrigações de natureza técnica, profissional ou militar, precisam, por isso mesmo, serem instruídos e orientados pelo governo, inclusive sobre os problemas palpitantes da atualidade, as suas soluções já aceitas ou definições o seu desdobramento e suas perspectivas futuras. [...] $\mathrm{O}$ governo atingiu com o decreto que criou a Juventude Brasileira a uniformização da educação da nossa mocidade, tenta assim, criar nos jovens uma mentalidade sadia, esclarecida e construtiva, a altura de poder servir, futuramente, aos destinos da nacionalidade. Para isso, objetivou que se lhe fossem proporcionados: 1- Instrução cívica; 2Instrução pré-militar; 3- Educação Física. (A DEFESA NACIONAL, 10/05/1944)

Em novembro de 1944, o Ten. Cel. Lima Figueiredo escreveu o artigo $A$ Engenharia Militar no Brasil, no qual analisou as reformas educacionais que influenciaram o campo militar, com especial ênfase na reforma Benjamin Constant. Ainda em novembro de 1944, o capitão Rui Alencar Nogueira escreveu o artigo Problemas da vida oficial, no qual tratava da questão da formação dos filhos dos militares e propunha a ampliação das Escolas Militares no país.

O ano de 1945 marca o fim da fase mais tecnicista de todas da revista. Os artigos desse ano pertinentes ao campo da educação foram bastante reduzidos. Uma nova característica se evidenciava: as matérias pagas, a maioria com caráter político. A questão da educação torna-se elemento de propaganda e não mais de ideal.

Uma das matérias da revista que tratou da questão educacional em 1945 foi $A$ Escola do Estado-Maior e a instrução, do coronel Renato Nunes, que ressaltava a importância da Missão Militar Francesa e a necessidade de se repensar a formação dos oficiais no pós-guerra. Propunha ainda a reinstalação da Escola de Alto Comando, fechada com a saída da Missão Militar Francesa. Outra matéria, também de Renato Nunes, chamada Reiterando um Apelo, tratava da importância do oficial sobre dois aspectos no campo militar: Psicologia e Pedagogia. Houve um retorno à idéia do oficial como professor.

Um último texto relevante foi publicado em dezembro de 1945, escrito pelo capitão Rui Alencar Nogueira Escola de Sub-Oficiais, no qual, seu autor analisou pontualmente a organização das escolas de suboficiais, especificamente a de Sargento de Infantaria.

\section{Considerações finais}

Os temas da revista A Defesa Nacional como civismo, moralismo e nacionalismo reforçam a argumentação de que os militares se sentiam superiores e os únicos capazes de apresentar à sociedade uma solução para os males que tanto a atormentavam. É fato que a maior parte do período republicano foi marcada por governos civis, mas sempre com intensas participações políticas de militares. $\mathrm{O}$ retorno à presidência por parte dos militares com o marechal Hermes da Fonseca, os movimentos políticos do "Dezoito do Forte", a "Coluna Prestes" e a própria revolução de 1930, que contou com intensa participação de muitos egressos do movimento tenentista, ratificam a ideia de que sempre foi interesse militar assumir o controle político. Novamente, o pretexto utilizado era o da regeneração moral da sociedade brasileira, corrompida pela degeneração dos valores e pela grande desigualdade social. 
A análise realizada até aqui leva à inferência de que o conteúdo dos textos da revista A Defesa Nacional publicados entre os anos de 1913 e 1945 aponta os principais problemas para a afetiva autonomização do campo militar e justifica o porquê das sucessivas aproximações do campo militar sobre o educacional. Parece claro que a autonomização do campo militar no Brasil trouxe consigo um projeto de nação. A fusão das teses dos benjaminianos com a dos jovens turcos foi de extrema importância para constatar que os militares não estariam só preocupados com o campo militar: era preciso um projeto de sociedade cuja educação teria um papel de destaque na regeneração social. Assim, por mais que o tema militar estivesse presente na revista, a discussão dos problemas nacionais também aparecia em destaque, cabendo à educação o papel de transformar a sociedade através dos ideais desenvolvidos pela categoria social mais eficiente, honesta e moral: a militar.

\section{Referências}

A DEFESA NACIONAL. Rio de Janeiro: Bibliex, anos de 1913 a 1969.

BARONI, Adelaide Cristina Brandão. A Revista A Defesa Nacional e o Golpe de 1964: um estudo sobre o discurso militar (1985-2004). In: II Encontro Nacional da Associação Brasileira de Estudos de Defesa, 7. 2008, Niterói. Anais do Evento. Niterói: UFF, 2008.

BOURDIEU, Pierre. A Economia das Trocas Simbólicas. São Paulo: Perspectiva, 2007. Os Usos Sociais da Ciência: por uma sociologia clínica do campo científico. São Paulo: UNESP, 2004.

COMTE, Auguste. Curso de Filosofia Positiva; Discurso Preliminar sobre o Conjunto do Positivismo; Catecismo Positivista. In: Os Pensadores. São Paulo: Nova Cultural, 1991.

CUNHA, Luiz Antônio. A Universidade Temporã: O Ensino Superior: da colônia à era Vargas. São Paulo: UNESP, 2007.

CURY, Carlos Roberto Jamil. Cidadania Republicana e Educação: Governo Provisório do Mal. Deodoro e Congresso Constituinte de 1890-1891. Rio de Janeiro: DP\&A, 2001.

HOLANDA, Sérgio Buarque de. Do Império à República. In: HOLANDA, Sérgio Buarque de. História Geral da Civilização Brasileira. São Paulo: Difusão Européia do Livro, 1972.

HORTA, José Silvério Baía. O Hino, O Sermão e a Ordem do Dia: a educação no Brasil (1930-1945). Rio de Janeiro: UFRJ, 1994.

LEMOS, Renato. Benjamin Constant: vida e história. Rio de Janeiro: Topbooks, 1999.

SCHULZ, John. O Exército e a Política. São Paulo: EDUSP, 1994.

SEPULVEDA, José Antonio Miranda. O papel da Escola Superior de Guerra na projeção do campo militar sobre o campo educacional. Tese de Doutorado em Educação.

Universidade Federal do Rio de Janeiro: Rio de Janeiro, 2010.

SODRÉ, Nelson Werneck. A História Militar do Brasil. Rio de Janeiro: Civilização Brasileira, 1979. 


\section{Notas}

${ }^{1}$ Doutor em Educação pela Universidade Federal do Rio de Janeiro. Mestre em Educação pela Universidade Federal do Rio de Janeiro. Especialista em História das Relações Internacionais pela Universidade do Estado do Rio de Janeiro. Licenciado e Bacharel em História. Professor Adjunto da Faculdade de Educação da Universidade Federal Fluminense no Departamento de Fundamentos Pedagógicos.

${ }^{2} \mathrm{O}$ conceito de campo usado neste trabalho foi desenvolvido por Pierre Bourdieu e significa um espaço complexo do mundo social, cuja estrutura interna é composta por um conjunto de relações de força entre agentes ou instituições próprias do campo.

${ }^{3}$ Esse termo foi utilizado a princípio como forma pejorativa, comparando-os aos jovens turcos que estudaram na Alemanha e fizeram a reforma do Império Otomano. Todavia, com o tempo, esse apelido tornou-se motivo de orgulho na corporação militar brasileira.

${ }^{4}$ Como esclarecimento é importante situar que em algumas citações que apresento não aparecem os números das páginas da revista A Defesa Nacional de onde foram transcritas, pois só em edições mais recentes é que esses números apareceram na referida revista.

${ }^{5}$ A proposta do cidadão-soldado era amplamente defendida pela juventude militar ligada a Benjamin Constant. A tese defendida por esse grupo baseava-se na ideia de que a caserna era o único lugar possível para a criação do espírito de solidariedade necessária para o bem geral da nação, e que a educação escolar deveria usar o quartel como exemplo.

${ }^{6} \mathrm{O}$ sorteio militar obrigatório foi a primeira forma de serviço militar obrigatório. Tal procedimento foi amplamente defendido pela Liga de Defesa Nacional, em especial pelo poeta Olavo Bilac. O sorteio era uma forma de se evitar que as forças políticas elitistas manipulassem o processo de recrutamento. Com o sorteio, toda a população masculina, independente de classe social, estava sujeita ao serviço militar. Esse modelo de sorteio, apesar de existir desde o final do século XIX, só entrou em prática a partir de 1916 e estendeu-se até fevereiro de 1945, quando foi instituído o serviço militar obrigatório com o formato que permanece até os dias de hoje.

${ }^{7}$ As principais potencias militares do mundo estavam estudando o valor do cinema para a educação da sociedade. Destaque para os alemães, soviéticos e norte americanos (Ferro, 2004).

Recebido em maio/13

Aprovado em novembro/13 